\section{Representaciones, discursos y prácticas profilácticas durante la epidemia de cólera (1886- 1887, Mendoza, Argentina)}

\section{Prophylactic representations, discourses and practices during the cholera epidemic (1886-1887, Mendoza, Argentina)}

Rosana Aguerregaray

Becaria postdoctoral, Instituto de Ciencias Humanas, Sociales y Ambientales/Centro Científico Tecnológico Conicet Mendoza. Mendoza - Provincia de Mendoza - Argentina

orcid.org/0000-0001-9665-6749

rosanaaguerregaray@gmail.com
AGUERREGARAY, Rosana.

Representaciones, discursos y prácticas profilácticas durante la epidemia de cólera (1886-1887, Mendoza, Argentina). História, Ciências, Saúde - Manguinhos, Rio de Janeiro, v.26, n.1, jan.-mar. 2019, p.187-207.

\section{Resumen}

El artículo busca indagar en los proyectos de disciplinamiento sancionados por el Estado de la provincia de Mendoza (Argentina) durante la epidemia de cólera ocurrida en el verano de 1886 y 1887. Si bien los planes tenían como finalidad mejorar el estado sanitario de toda la población y de la ciudad, apuntaron y se aplicaron con mayor intensidad sobre los sectores populares y sus espacios. Esto se debió a las ideas y representaciones que en torno de la enfermedad y la muerte construyó el grupo dirigente durante estos periodos.

Palabras clave: Mendoza; cólera; higienismo; Estado; pobres.

Abstract

The article takes a look into the disciplinary projects approved by the authorities in the province of Mendoza (Argentina) during the cholera epidemic that took place during the summer of 1886-1887. Although the projects were intended to ameliorate the sanitary conditions of the whole of the population, these were focused and applied more intensively on the underprivileged sectors and their areas of inhabitance. This follows the ideas and representations created by the State regarding the illness and its death during this period.

Keywords: Mendoza; cholera; sanitary; State; underprivileged. 
$\mathrm{E}^{1}$ presente artículo tiene como objetivo analizar los planes de disciplinamiento emanados desde la esfera gubernamental en torno de la enfermedad en momentos clave, es decir, durante el desarrollo del cólera en 1886-1887, en la provincia de Mendoza, República Argentina. De este modo, se busca indagar en los discursos y comportamientos que condicionaron la construcción de la noción de "peligro" elaborada por el grupo gobernante durante ese lapso, y el modo en que estas representaciones ${ }^{1}$ atravesaron ciertas políticas que decían tener como objetivo último el mejoramiento del estado sanitario de toda la población.

De tal forma, la hipótesis que guía el análisis sostiene queel Estado provincial buscó controlar y regular las prácticas y costumbres a través de diversos dispositivos, no obstante, este accionar fue aplicado con mayor incidencia sobre los sectores pobres. Esto se debió a las representaciones que en torno de la enfermedad construyó el grupo dirigente durante esa coyuntura, asociándola a las prácticas y a los hábitos privados de los menesterosos aseo personal, hábitos alimenticios, condiciones de viviendas, actividades de ocio, espacios de sociabilidad -, en donde el Estado debía intervenir ya que esas cuestiones, según ellos, pertenecían al campo de lo público.

Para ello, se analiza tanto las normativas y los discursos de los actores políticos manifestados a través de la prensa local, los informes técnicos médicos y de salubridad pública que fueron realizados durante y después de las pestes.

El trabajo se encuentra organizado del siguiente modo: en un primer momento se hace referencia a las condiciones sanitarias de la provincia durante fines del siglo XIX. En un segundo momento, se centra en las ideas que acerca de la enfermedad y del "peligro" reinaba en el imaginario de la época, para luego hacer hincapié en la epidemia de cólera.

\section{Condiciones sanitarias de Mendoza durante fines del siglo XIX}

Durante fines del siglo XIX, las enfermedades devinieron en un problema social, ya que se las comenzó a vincular con otras urgencias, convirtiéndose en una necesidad primordial el tratar de evitarlas y gestionarlas por medio de políticas públicas. De este modo, la higiene adquirió un rol fundamental tanto en sus "contenidos preventivos como disciplinadores" (Armus, 2000, p.511). A lo largo de ese periodo, la provincia de Mendoza (Figura 1) fue víctima de numerosas enfermedades: cólera, viruela, difteria, escarlatina y tuberculosis. Esta situación crítica se vinculó con un acentuado crecimiento demográfico y urbanístico producido desde 1880, cuando simultáneamente no se disponían de los medios materiales necesarios para propiciar en la ciudad un entorno sanitario adecuado, provocando los "primeros desajustes de un ambiente urbano cada vez más vulnerable donde las epidemias no distinguían entre ricos y pobres" (Cirvini, 1989, p.108). A ello se sumaron las malas condiciones en las que se encontraba la antigua ciudad colonial, destruida tras el terremoto de $1861^{2}$ y que hasta el momento contenía sus propios escombros; allí, la falta de limpieza e higiene la convertía en un posible foco de infección para toda la población. Por su parte, la escasez de los servicios, tales como el alumbrado público, la nivelación de las calles y fundamentalmente, el agua corriente domiciliaria agravaron la situación, del mismo modo que lo hicieron la llegada del ferrocarril, el crecimiento de la inmigración y, con eso, los 


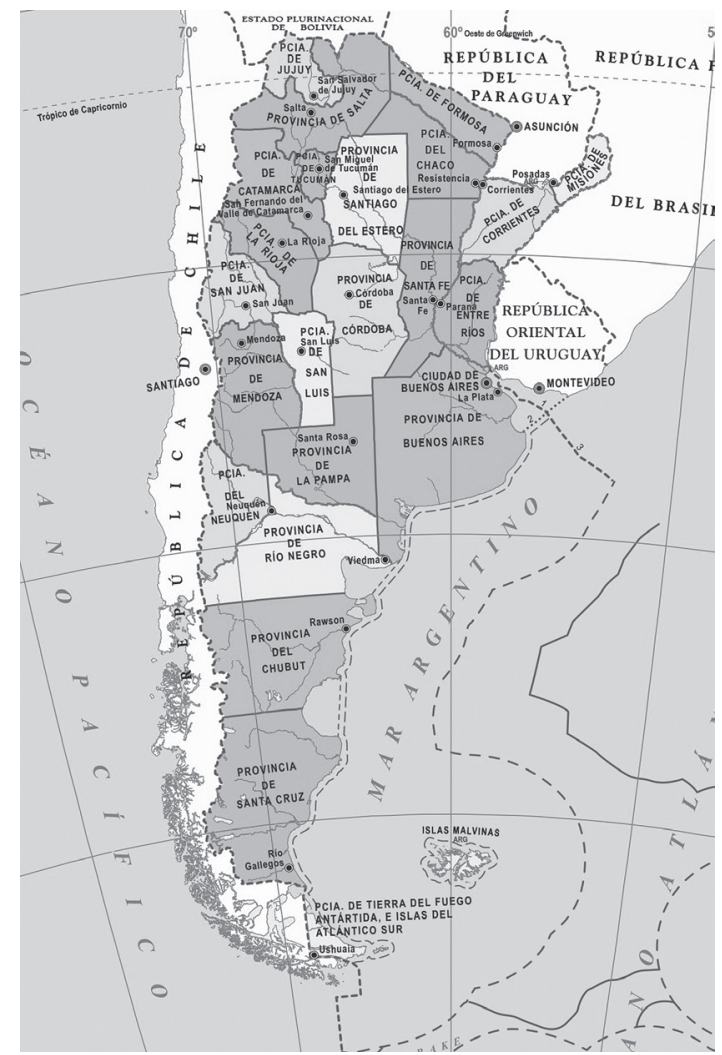

Figura 1: Mapa con la localización de la provincia de Mendoza, República Argentina (Argentina, s.d.)

conventillos; de hecho, no es casual que el primer caso de cólera se registrase en este tipo de viviendas (Cirvini, 1989).

De estas cuestiones, el principal problema sanitario que debía enfrentar la provincia era el agua potable, la cual era distribuida por medio de una red hídrica de canales que se ramificaban en una serie de acequias atravesando las manzanas. En 1876 se hicieron los primeros trabajos sistemáticos en cuanto a su provisión, reparándose el acueducto del Challao (proveía de agua a la ciudad colonial, desembocando en la fuente de la plaza Pedro del Castillo), colocando filtros para la purificación y una red de surtidores públicos en la actual calle San Martín y en la Alameda, pero quedaba fuera de este servicio la mitad norte de la ciudad antigua a pesar de ser la zona más poblada. En este mismo año se realizaron las conexiones domiciliarias en la nueva ciudad y se extendió la red de surtidores para lograr cubrir una parte importante de la sección este. En 1885, a su vez, se establecieron las conexiones de agua para edificios públicos como el hospital San Antonio y se colocaron más surtidores en la ciudad nueva y vieja (Figura 2). Como gran parte de la población debía beber agua potable de esos surtidores públicos y ellos no cubrían todo el territorio, también las acequias la proveían para el consumo cotidiano, aunque estas zanjas eran usadas además como desagüe cloacal. Esto explica que se considerara, con razón, a las acequias como principales focos de infección y de generación de enfermedades, todo lo cual dejaba 


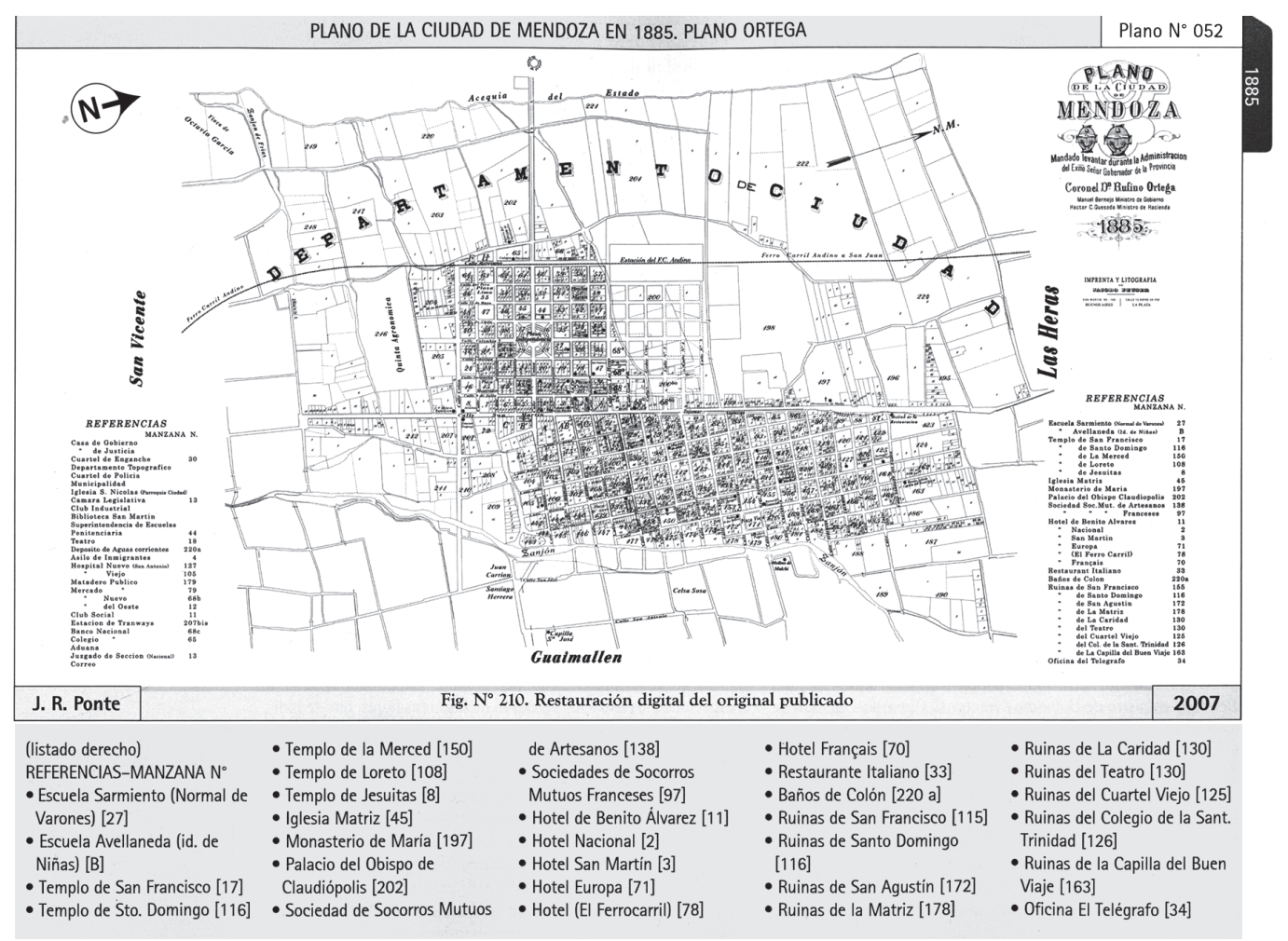

Figura 2: Plano de la Ciudad de Mendoza, Argentina, en 1885 (Ponte, 2008, p.253)

en claro la urgencia de resolver de forma inmediata los sistemas de distribución no solo de agua potable sino también de cloacas y de desagües colectores pluviales (Cirvini, 1989).

Las instituciones que debían velar por la salud e higiene pública de la población de la ciudad eran el gobierno provincial y la municipalidad. Pero, esta última institución, creada en 1868, era en sus inicios más bien una construcción legal que contaba con un sistema deficitario e ineficiente. Hacia 1880, con la llegada de Luis Lagomaggiore a la presidencia del municipio, comenzó a tener una estructura más ejecutiva; entre algunos de sus proyectos se propuso integrar la antigua ciudad a la nueva para poder controlar el estado sanitario del sector que, como se mencionó, se había convertido en un foco de infección. De este modo, Lagomaggiore comenzó a darle a esta institución una organización que permitió hacer efectivas las políticas gubernamentales sobre el espacio urbano, montando "dispositivos de control sobre la ciudad que con el tiempo elaboraron normas de disciplinamiento social, vinculadas a la vida urbana (salud y enfermedad, vivienda, usos del espacio público)" (Cirvini, 1989, p.112). Esto respondía a un estado provincial que se encontraba en conformación y que por lo tanto aplicó una serie de mecanismos disciplinares en donde las políticas estatales estaban influenciadas por el positivismo, lo cual le otorgó legitimidad a los proyectos políticos, brindándole argumentos, políticas y soluciones para articular "los espacios institucionales, las tecnologías de poder y la retórica" que eran necesarios "para ejercer el poder con más eficacia en una sociedad que se masificaba y democratizaba" (Salvatore, 2001, p.83). 
De este modo, Lagomaggiore fue el iniciador del plan urbanístico sanitario que convirtió el ambiente urbano en objeto de atención y de estudio, y utilizó a la higiene social para legitimar las políticas propuestas desde la esfera gubernamental (Cirvini, 1989). Sin embargo, durante su intendencia se desató la epidemia de cólera, entre fines de 1886 y principios de 1887 (al igual que en otras provincias de la Argentina), provocando un gran número de víctimas, el mayor hasta ese momento en la historia sanitaria de la provincia. A diferencia de Buenos Aires, en donde tuvo menor alcance, a pesar de que fue la "puerta de ingreso", probablemente debido a que los principales barrios contaban con servicios básicos, tales como el agua corriente y los desagües cloacales (Álvarez, 2012).

No obstante, el azote de esta peste sirvió como disparador del proyecto higienista que hasta el momento era solo un boceto, y por medio de éste, la elite dirigente intentó estructurar el espacio urbano de acuerdo a una "estrategia de diseminación de controles" (Vallone, 2009, p.39) para, de este modo, ocultar y reprimir todo aquello que no se quería visibilizar. En este sentido, no se buscó organizar el espacio en su dimensión material, sino "normativizar su uso, generar una nueva interpretación de lo real y de lo simbólico de acuerdo a los valores hegemónicos" y, así, redefinir los peligros que amenazaban con la decadencia de la vida urbana (Vallone, 2009, p.39). Se intentó controlar y disciplinar a los sectores más desprotegidos para procurar dominar el espacio urbano y, así, tratar de construir su utopía del orden, basada en la seguridad y el progreso. Estas ideas eran concordantes con un plan nacional "de reorganización urbana y de control de las viviendas y enfermedades populares", donde la preocupación de los higienistas estuvo centrada en aquellas enfermedades que derivaban de los hacinamientos y de las condiciones de vida de los sectores pobres escasamente instruidos (Caponi, 2002b, p.116).

En Mendoza, luego de la epidemia de cólera, se hicieron modificaciones en el ambiente urbano buscando mejorar la calidad de vida a través de la aplicación de una serie de normas y estrategias planificadas y de la inversión en obras sanitarias (Cirvini, 1989). Sin embargo, a pesar de los esfuerzos por mejorar el estado sanitario de la ciudad, continuó desarrollándose una sucesión de epidemias. Según registró el médico Emilio Coni (1897), ${ }^{3}$ entre los meses de mayo y agosto de 1889, se desató con mayor intensidad la viruela, mientras que durante los meses de invierno (marzo a agosto) de 1890 a 1895 se registraron los índices más elevados de defunciones a causa de la difteria, afectando sobre todo a la población infantil. A su vez, en el último año mencionado también hizo su aparición la escarlatina (Coni, 1897).

Además de las enfermedades infectocontagiosas, otra causa de muerte estaba vinculada a las gastrointestinales, las que en algunos años superaron a las infectocontagiosas. Si bien este tipo de dolencias no irrumpían de forma sorpresiva sobre la vida de los sujetos como lo hicieron las infectocontagiosas, eran parte de la trama social, aunque "no lograban movilizar recursos materiales, profesionales o simbólicos suficientes para ser percibidas como serios problemas colectivos" (Armus, 2005, p.189). Podemos observar que la ciudad de Mendoza, devastada por "temibles epidemias, [presentaba] un promedio de morbilidad que no tiene igual en las capitales más populosas, con una despoblación alarmante ... De nada sirve la riqueza y el grandioso porvenir de un país, si por los hechos éste se ha transformando en una inmensa necrópolis" (Coni, 1897, p.530). 
Con posterioridad al informe de Emilio Coni, comenzaron a tomarse medidas que fueron más sistemáticas en cuanto a la rigurosidad de su aplicación, con lo cual el proyecto higienista adquirió un mayor y nuevo impulso. Se construyó el Hospital Provincial, se reactivaron la Oficina Química y la Dirección de Estadística, y se creó la Dirección General de Salubridad. Se sancionaron nuevas ordenanzas para la edificación de letrinas, la regulación de la prostitución y de casas de tolerancia (Cirvini, 1989). Por otra parte, también se impulsó la promoción de la higiene privada a través de la escuela y la familia (Ponte, 1999); así, a través de la educación, "se confiaba el perfeccionamiento del individuo y el aumento de su rendimiento como valor social, ... el deber de cuidar ... la cultura física, ... intelectual y moral del niño" (Vallone, 2009, p.92).

Sin embargo, hacia 1906, el diario Los Andes seguía manifestando que era lamentable el estado sanitario de la provincia, ya que las enfermedades infectocontagiosas continuaban siendo endémicas y epidémicas, siendo más afectados la población de recién nacidos y los menores de 5 años. Además, expresaba que tanto el organismo provincial como municipal carecía de una burocracia administrativa y profesional que pudiera articular y efectivizar las políticas públicas propuestas por Coni (Ponte, 1999). No obstante, este proyecto higienista le brindaba a la elite gobernante los argumentos para justificar las medidas empleadas tanto en el ámbito público como privado, las cuales buscaban disciplinar y controlar a la población y, de este modo, "el espacio urbano se transformaba en causa y efecto de un proceso más amplio de control y disciplinamiento social y político que constituía el soporte imprescindible del proyecto político del orden y el progreso en que estaba embarcada la dirigencia política mendocina" (Ponte, 1999, p.236).

Según Cerdá (2006), la Mendoza finisecular se asemejaba más a una sociedad tradicional (con alta tasa de natalidad y mortalidad) que a una que estuviese en pleno proceso de modernización. No obstante, de forma progresiva durante el periodo comprendido entre 1890 y 1914 hubo una disminución de la tasa de defunción, pues de un 59\% bajó a un $22 \%$. En fin, si bien el estado sanitario de la ciudad a fines del siglo XIX no era adecuado, comenzó a articularse un sistema de salud (asistencia pública, profilaxis, médicos) que iría mejorando su eficiencia durante el transcurso del siglo XX.

\section{Entre los discursos y las medidas de urgencia: las epidemias, el gobierno, los médicos y los enfermos}

A fines del siglo XIX e inicios del XX, tanto desde la esfera gubernamental provincial como nacional, se inició un plan de políticas preventivo-sanitarias centradas en el mejoramiento de la higiene social y la salud pública. Más allá del tinte político, consideraban que era necesario una reorganización social que permitiera combatir las constantes epidemias que diezmaban a la población y los males que afligían a la ciudad (Armus, 2000). Hubo una marcada preocupación por lo urbano, constituyendo uno de los ejes de la medicina colectiva y social "que pivoteaba sobre los avances de la bacteriología moderna, el desarrollo de la estadística como disciplina, la consolidación de instituciones estatales con agendas específicamente abocadas a las cuestiones de la salud pública, la creciente presencia de la profesión médica en la sociedad y el Estado" (Armus, 2007, p.275). 
Por medio de la higiene social se buscó dar a la elite un entorno urbano seguro y controlable desde el punto de vista epidémico y alejar a ciertos sectores del peligro del contagio e incluirlos en el mundo social moderno como trabajadores respetables y eficientes (Armus, 2007). En este sentido, en los discursos enunciados en la prensa y en los informes médicos, las medidas debían esforzarse por regular las conductas y los hábitos privados y públicos de los sectores más vulnerables, interviniendo en sus modos de vida, tradiciones y actividades sociales para mejorar la calidad sanitaria en general. Las autoridades provinciales y municipales eran quienes debían ejecutar su cumplimiento a través de la vigilancia y el castigo, mientras que en la esfera privada era el patrón quien las debía efectuar por medio de los mismos mecanismos (Policia..., 22 dic. 1886). De tal modo, "tanto las autoridades como las personas acomodadas deb[ían] regular las prácticas de los pobres" (Policia..., 22 dic. 1886). En síntesis, el objetivo era dirigir y organizar la vida de estos sujetos buscando el orden, la obediencia y el acatamiento de ciertas normas (Gargiulo, 2011).

\section{De las concepciones miasmáticas a la teoría microbiana}

Los avances de la bacteriología no fueron incorporados y aceptados de forma inmediata y coexistieron durante gran parte del siglo XIX con muchas de las explicaciones vinculadas ala teoría miasmática, ${ }^{4}$ tal como el descubrimiento del bacilo Koch. En las enfermedades, por ejemplo en el caso particular de la tuberculosis, se adoptó un relato etiológico que "reconocía la existencia de una alteración del flujo de fluidos en el cuerpo generada por la presencia de materias externas que disparaban un progresivo deterioro, siendo los propensos a contraer la enfermedad los pobres, delgados y débiles, los que vivían en ambientes urbanos insalubres, los que sufrían afecciones morales y practicaban excesos venéreos, los que llevaban una vida sedentaria, por cuestiones hereditarias" (Armus, 2007, p.137-138). Así, las pestes continuaron asociadas a las viviendas, la herencia biológica, las costumbres de aseo y alimentación, al campo laboral y a los sectores de menor poder adquisitivo (Armus, 2007).

Tal como menciona Corbin (2002, p.245-246) para el caso francés, la revolución pasteuriana ejerció una influencia en las representaciones y las estrategias sociales, ya que la irrupción del germen microbiano imponía volver a tratar la cuestión de la epidemiología. De este modo, "todas las aguas debían declararse sospechosas ... y todos los individuos también", aunque continuó vinculándose los gérmenes con la suciedad y con las clases pobres de una manera sutil.

Asimismo, continuaron las mismas estrategias sanitarias ideadas para controlar las epidemias. Varias de las medidas clásicas - desinfección, detección y posterior destrucción de focos de infección, control de las viviendas y de los barrios populares - que fueron aplicadas por los higienistas, en su gran mayoría infeccionistas, lejos de desaparecer encontraron en las investigaciones pasteurianas un sustento teórico (Caponi, 2002c, p.592). Tanto los pre como pos-pasteurianos consideraban que la amenaza parecía estar en el aire, en el ambiente donde se respira (p.606). Así, la nueva higiene - heredera de la microbiología - "no necesitaría romper con mitos climáticos ni superar las ideologías del pesimismo sanitario. No venía a negar sino auxiliar y a legitimar las intervenciones de los higienistas clásicos preocupados por el saneamiento urbano" (Caponi, 2002a, p.125). Tal como sostiene 
Caponi (2002a), hubo una articulación entre los clásicos y los nuevos higienistas, cuyas estrategias se proponían combatir aquello que amenazaba el estado sanitario de la ciudad y la población. Tanto para los higienistas pre como pos pasteurianos su discurso giró en torno de la vivienda popular, la pobreza y la desigualdad social.

Las nuevas ideas de higiene, originadas de aquella revolución bacteriológica del último tercio del siglo XIX, fueron incorporándose paulatinamente en prácticas sociales, terminando por convertirse muchos de sus principios en necesidades materiales y morales de la vida en la ciudad moderna. Las nuevas conductas higiénicas implicaron un esfuerzo de "marketing social", tanto a fines del siglo XIX, cuando dominaba un discurso basado en el temor y una higiene defensiva que combatía todos los peligros, como a partir de los años 1920, cuando se centró en la vida sana y la higiene positiva. Su disgregación se inició, entonces, como "una consecuencia del pánico al contagio, transmutó en una cuestión de salud pública, particularmente relevante en la vida de los pobres, y se fue centrado en ciertos grupos sociales, definidos ante todo por su ocupación o su vivienda y no tanto, como en el pasado, por sus estilos de vida o su moralidad" (Armus, 2007, p.398).

Durante fines del siglo XIX, en Mendoza, las ideas y discursos también comenzaron a ser deudores de esta creencia, como se deja ver en la prensa durante el desarrollo de la epidemia de cólera. En un artículo se solicitaba a las autoridades municipales que los carros fúnebres que trasladaban los cadáveres coléricos por la calle Bolivia hacia el cementerio, fueran conducidos por otras vías menos pobladas, ya que los vecinos no podían ventilar sus viviendas por temor al contagio (Reclamo..., 22 dic. 1886). Simultáneamente comenzaban a aparecer otros discursos contrarios a estas creencias que afirmaban que el cólera no se transmitía porque la persona exhalara el aire en donde se encontraba el cuerpo, pues por ese medio no se trasmitían los gérmenes (Entremos..., 22 dic. 1886).

A partir de la microbiología se introdujeron saberes médicos que marcaron un punto de partida del poder médico sobre el resto de la sociedad. Según Di Liscia (2000), el control médico fue un proceso que implicó esfuerzos tendientes a homogeneizar las prácticas y no una cuestión automática en la que autoridades acordaban totalmente entre sí y con los facultativos e instituciones sanitarias. Estos profesionales tuvieron que negociar el establecimiento de su autoridad sobre la sociedad, vinculándose con las diferentes instituciones estatales y estableciendo al mismo tiempo de forma fehaciente una capacidad superior para resolver problemas de salud urgentes, tal como fueron las epidemias. De este modo, para principios del siglo XX, el médico era la única voz autorizada con injerencia sobre el cuerpo humano, "a quienes la eugenesia brindó nuevas posibilidades de actuación y de pedagogía social frente a las 'masas' incultas" (Di Liscia, 2000, p.404-405; énfasis del original). El médico delinearía las directrices sobre hábitos de higiene y reformas urbanísticas y, así, alcanzaría un status social y político. Durante este periodo, los médicos tenían más incertidumbres que certezas en relación a su propio saber. Hasta ese momento no habían consensuado las causas y las curas de las enfermedades epidémicas y endémicas. La medicina y el saber médico constituían un campo en conformación que formaba parte de un proyecto modernizador que estaba atravesando la región (Chaves, 2013). A fines del siglo XIX, la figura del médico - vinculado al "positivismo" - "se ubicó en el centro dela escena político-social. Se habla de una afianzamiento para entonces de un dispositivo 
médico-ideológico y también de una creciente 'medicalización' de la sociedad" (González Leandri, 2000, p.422; énfasis del original).

Según Vezzeti (1985, p.38), por medio del higienismo, la burguesía encontró el argumento válido para construir una nueva figura de "reformador social, ungido por la ciencia y los ideales filantrópicos", a la vez que le permitió la afirmación y legitimación de la conciencia médica, configurando estrategias de consolidación del aparato del Estado, concordantes con la política argentina de 1880. A fines del siglo XIX el Estado comenzó a implementar una serie de políticas sanitarias en vinculación con el "campo científico", otorgando a la figura del médico un lugar destacado y reafirmando su poder como experto, a diferencia del curandero, colocado en un rol de ignorante y vinculado al saber popular (Di Liscia, 2000). En la provincia, la Dirección General de Salubridad persiguió al curanderismo para favorecer a los médicos (Los médicos..., 14 mayo 1926) y a las clases pobres, ya que se decía que abandonaban a sus moribundos en manos de los curanderos (Lemos, 1897, p.170). En ese sentido, se buscó alejar a dichos grupos de las "explotaciones y errores" de los charlatanes y difundir "las prescripciones científicas que curan y evitan las enfermedades e impiden su propagación (sic)" (Mendoza, 1903, p.57-58).

\section{Noción de peligro}

Tal como se mencionó, hacia fines del siglo XIX comenzó a gestarse un nuevo concepto de salud vinculado a la medicalización de la sociedad y al rol creciente de los médicos en todos los aspectos de la vida de las personas: sus enfermedades, su alimentación, su moral; de este modo, la salud era entendida como una trama articulada de bienestar físico, psíquico y moral. Todo esto dio lugar al concepto de higiene social, la rama de la medicina que intentaba evitar que unos pocos sujetos por medio de sus dolencias menoscabaran el cuerpo social, con el cual se volvió necesario el control de los sectores considerados potencialmente peligrosos para cuidar la salud del resto de la población (Ferrari, 2014).

La medicina de la época, influenciada por el positivismo ${ }^{5}$ y basada en la medición y experimentación, consideraba que lo "normal" era todo aquello que era cuantificable, medible, identificable, buscando detectar aquello que era entendido como anormal para poder proteger a la población. En Argentina, los estudios médicos se centraron en la higiene tanto privada como pública y en el análisis de la marginalidad, el hacinamiento y las enfermedades sociales. Algunos de los médicos que se desarrollaron en este campo ocuparon cargos públicos, con lo cual las inquietudes personales se transformaron en problemas políticos (Ferrari, 2014).

Así, por medio del higienismo se determinaron las políticas estatales sanitarias y de salud, y se establecieron normas que permitieron el control y disciplinamiento de la población. Además, este discurso "recorrió el entramado social inaugurando una nueva manera de concebir lo 'peligroso' (peligro biológico), resignificando objetivos de la defensa social (por lo que bajo una concepción biológica cobraba fuerza el imperativo del individuo como único custodio del plasma germinativo)" (Vallone, 2009, p.72; énfasis del original). Lo peligroso fue considerado como todo aquello que atentaba contra el orden establecido y que provocaba un desajuste en el proyecto hegemónico de la Argentina moderna, basado en 
el orden y progreso. El discurso higienista se centró en la preservación de la raza, la salud y la moral y, a partir, de la configuración de la categoría de lo "peligroso", comenzaron a delinearse los espacios marginales de contención de estos sectores, tales como los arrabales y los conventillos, así como también, las pautas culturales asociadas a la miseria, el alcoholismo, las enfermedades y la prostitución (Vallone, 2009). Más allá de los avances de la bacteriología moderna, las ideas y las representaciones sobre la enfermedad y el contagio continuaron asociándose a los sectores populares, vinculados con la peligrosidad moral, política y médica (Caponi, 2002a).

Estas tramas conceptuales también se vieron reflejadas en las ideas y discursos de la elite mendocina ${ }^{6}$ durante el desarrollo de la epidemia de cólera, siendo posible vislumbrar dos matizadas voces ambas pertenecientes a dicho grupo. Por un lado, estaban los sujetos que pertenecían al sector dirigente, quienes entendían que era su deber aplicar políticas públicas en busca del disciplinamiento de la población, y por el otro, aquellos que no, pero que tenían injerencia en el campo público e interpelaban a este grupo por medio de las sugerencias o críticas que debían realizarse durante estas coyunturas. En varias ocasiones este discurso político y científico, apoyado por las autoridades eclesiásticas, se entrecruzó con cuestiones de carácter religioso para legitimar las argumentaciones sobre el brote, como se verá en el siguiente apartado.

\section{“A quién le venga el sayo...": discursos de la elite durante la epidemia de cólera}

En los comienzos de la epidemia, las autoridades, al igual que en otras provincias de la Argentina (Álvarez, 2012), optaron por ocultar los casos. Sin embargo, la prensa local daba lugar a extensas notas acerca de cómo prevenir y curar esta dolencia. Además, denunciaba que se adulteraban los certificados de defunción, atribuyendo la causa de muerte a enteritis producida por desarreglos alimenticios, e incluso, hasta el mismo lazareto municipal "afirmaba que todos los enfermos que allí morían no eran coléricos, sino borrachos consuetudinarios, octogenarios que habían comido fruta verde, enfermos crónicos incurables" (Lemos, 1973, p.134). A todo ello se sumaba la prohibición en torno de la publicación de las listas de defunción con sus respectivas causas. Ante esta situación, desde el periódico se solicitaba que se esclareciera la presencia de dicha enfermedad, ya que cuando se producía un caso sospechoso la municipalidad ocultaba el diagnóstico y vetaba que se hablara del hecho, impidiendo así que se procediera de forma inmediata a la aplicación de las medidas que la ciencia aconsejaba, entre otras, la quema de la cama y ropa de la víctima, fomentando, por el contrario, la "fantasía popular" e introduciendo la alarma en los barrios (¡El cólera..., 16 dic. 1886). Este silencio por parte de las autoridades buscaba evitar el pánico del pueblo pero la situación provocada era inversa, haciéndose insostenible, ya que en un día fallecieron 78 personas no contándose con el personal necesario para poder dar sepultura a los cuerpos (Lemos, 1973). ${ }^{7}$ Según registró Emilio Coni, durante estos años, el 31\% de las defunciones fue a causa de esta enfermedad (Gráfico 1). ${ }^{8}$ 


\section{Gráfico 1: Defunciones de los años 1886 y 1887}

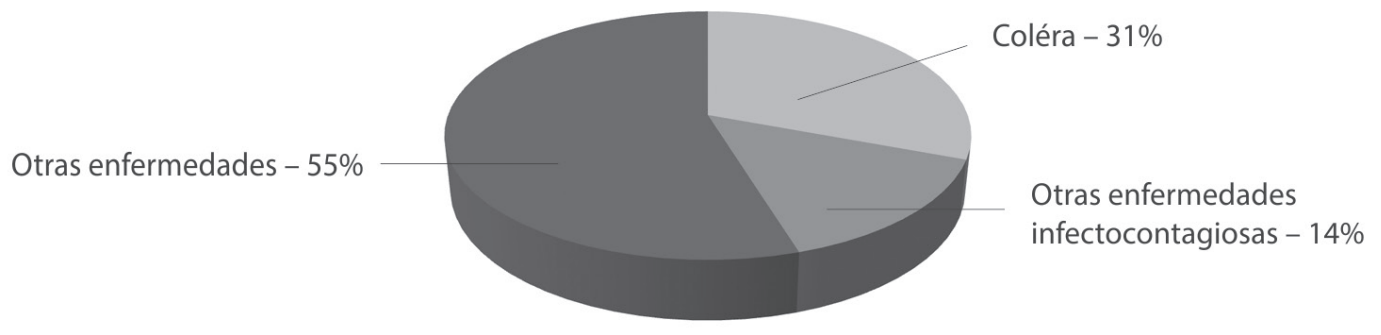

Fuente: elaboración propia a partir de los datos de Coni (1897, p.446-447).

En este marco, la elite gobernante implementó una serie de medidas preventivas para combatir la epidemia. Una de ellas, fue retener en las zonas limítrofes los trenes procedentes de otras jurisdicciones (El cuerpo..., 10 nov. 1886). Allí, los pasajeros eran aislados y colocados bajo observación durante siete días (La cuarentena..., 27 dic. 1886). Esto coincidía con las medidas profilácticas emanadas desde los países centrales, tal como lo pautó la Conferencia Internacional de París (1894) (Álvarez, 2004). A ello, se sumaron, tal como observa Álvarez $(2004,2012)$ para el caso de Buenos Aires, la desinfección y quema de objetos y el aislamiento en lazaretos, las cuales fueron propuestas por los "contagionistas", quienes sostenían que las dolencias se transmitían por el contacto con el enfermo y sus enseres. No obstante, las mediadas de los "anticontagionistas", quienes afirmaban que las condiciones atmosféricas y los vientos transmitían los miasmas y favorecían el desarrollo de la enfermedad, también fueron aplicadas sobre la población y sus espacios, tal como fue la desinfección de las viviendas, la destrucción de los focos de infección y de putrefacción (tales como los cadáveres o los residuos orgánicos) (Caponi, 2002c).

De este modo, los métodos de aislamiento acerca del agente generador del cólera, efectuados con anterioridad al descubrimiento de Koch, expresa lo planteado por Caponi, de que los "contagionistas", "preocupados por las cuarentanas y los lazaretos, actuaban como si la existencia de los gérmenes ya estuviera comprobada" (Álvarez, 2012, p.182). Por su parte, "los "infeccionistas" no necesitaron esperar a que la microbiología produjera sus pruebas para recomendar y ejecutar medidas de desinfección mucho antes que el vibrión colérico o las bacterias específicas de las diferentes enfermedades pudieran ser identificadas o siquiera imaginadas" (Álvarez, 2012, p.182). Así, los dispositivos de aislamiento, higiene y control vinculados ala circulación de sujetos y objetos, vigentes desde los años sesenta, fueron medidas que no se diferenciaban de lo que más tarde promovió la bacteriología (Álvarez, 2012). Tal como lo muestra Chaves (2013), tanto para las regiones del Río de la Plata como del Brasil, se utilizaron similares medidas para aislar y observar a las personas y enseres por un lapso de tiempo y bajo condiciones estrictas para descartar posibles contagios o transmisiones.

Durante ese momento, el grupo dirigente mendocino construyó sus discursos normativos basados en nociones provenientes tanto del campo científico como del religioso y en ellos sostenía que el principal causante de esta enfermedad eran las costumbres de la 
población. No obstante, era claro que no eran los hábitos de toda la población sino los de las clases pobres, ${ }^{9}$ los principales generadores, considerándose a sus espacios de habitación y sociabilidad como focos de infección y propagación; de tal forma, esta era conceptualizada como una enfermedad de tipo "popular" (Buenos Aires, 1887), en una ecuación en la que los médicos sociales tanto como los higienistas terminaron de asociar la pobreza con la enfermedad (Salvatore, 2001). En este registro, las autoridades se propusieron hacer cumplir todas las medidas profilácticas que se pautaran, estipulando que en caso de incumplimiento los infractores serían multados (Hijiene..., 3 dic. 1886), justificando "hasta el empleo de la fuerza, si la ignorancia o el interés ... pretendiesen oponerse a sus benéficas determinaciones" (Buenos Aires, 1887, p.5). De este modo, se adoptaron medidas que segregaban a los sectores populares, a los cuales se les atribuía la culpa del desarrollo de las enfermedades infectocontagiosas (Cueto, 1997).

La elite vinculó la noción de "peligro" con todo sujeto, objeto o acontecimiento asociado a estos sectores y a sus ámbitos urbanos, tal como en Mendoza eran la ciudad antigua y los arrabales. Estas consideraciones fueron deudoras del concepto de que la enfermedad era causada por algún factor exógeno al cuerpo humano (Ponte, 1999), por lo que, por ejemplo, durante la intendencia de Lagomaggiore se expulsó hacia los arrabales todo aquello que era considerado peligroso "como si las bacterias y la contaminación supieran de límites" (Cirvini, 1989, p.112). De tal forma, se indicaron aquellos lugares que eran propensos para el desarrollo del cólera, siendo uno de estos las grandes ciudades donde se producía el hacinamiento de la población, suponiéndose que "mientras más gente hay menos higiene (sic)", así como también, los hospicios de dementes, donde "la epidemia ha hecho pues, su segunda elección en otra agrupación densa, en que las reglas individuales de higiene son de difícil observancia, por la situación moral de aquellos infelices y hasta por la depravación de sus inclinaciones y apetitos (sic)" (Las aglomeraciones..., 10 dic. 1886). Tal como plantea Caponi (2002c), a pesar de los adelantos en materia de bacteriología, continuó asociándose la pobreza con la inmoralidad, y la preocupación de los profesionales vinculados a la salud giró en torno de las condiciones de vida de los sectores populares.

También los conventillos se consideraron focos de peligro por el hacinamiento, independientemente del modo en que se pensaba la etiología de las enfermedades. Desde Wilde hasta Coni, la preocupación por este tipo de viviendas y sus estrategias de higienización se reiteraban más allá de la creencia enlos miasmas o microbios (Caponi, 2002a). No obstante, se consideraba que por ser de menores dimensiones, estaban "más sujetos a la observación de las comisiones sanitarias y [podían] ser desalojados cuando se encuentren en condiciones peligrosas", es decir, se creía que el cólera buscaba poblaciones densas y en malas condiciones de higiene (Las aglomeraciones..., 10 dic. 1886). Así, durante el desarrollo del flagelo, las Comisiones de Comercio recorrieron los barrios más pobres de la ciudad, llegando a un diagnóstico altamente negativo, con una gran cantidad de enfermos y varios muertos, quienes no habían recibido el auxilio correspondiente y fallecían sin asistencia médica, sin pan y sin remedios (La epidemia..., 23 dic.1886). Se generaba un círculo vicioso por el cual se desplazaba a estos grupos hacia ciertos ámbitos considerados potencialmente favorables al desarrollo de las enfermedades debido a sus 
costumbres supuestamente poco higiénicas, pero a la vez, se estigmatizaba esos mismos espacios, intentando controlarlos a partir de diversos dispositivos.

En este contexto, el sector este de la ciudad fue asociado a los sectores pobres y, por lo tanto, considerado una constante amenaza para el resto de la población, además de que en este sitio se encontraban las ruinas de la antigua ciudad donde todavía habían restos de las víctimas del terremoto, así como también, todo tipo de basuras e inmundicias (Una idea..., 21 ene. 1887). A diferencia de esto, el sector oeste, asociado a las clases más acomodadas, se creía que tenía un buen estado higiénico debido a eso contaba con muy pocas defunciones a causa del cólera (La verdad..., 11 ene. 1887). Por ello, se constituyeron varias comisiones, entre las cuales, la de Comercio y de Vecinos, que tenían el deber de inspeccionar los domicilios y determinar las medidas que debían efectuarse en un tiempo pautado, porque en caso contrario se multaría al propietario (Observaciones..., 28 dic. 1886), así como también, la asociación de la Cruz Roja y Popular ofrecieron auxilios a los enfermos en los sitios más alejados de la provincia (Mendoza, 1888). De este modo, el visitador consistía en un elemento clave para garantizar la eficacia de las estrategias de asistencia y moralización, ya que debía verificar las condiciones sanitarias de aquellos alojamientos considerados insalubres y determinar su destrucción. Luego, tendría una función preventiva que permitiría reforzar y extender el control sobre dichos espacios (Caponi, 2002a).

No obstante, hacia noviembre de 1887 (luego del cólera), se manifestaba que la sección este continuaba con las "calles sucias, llenas de lodo, polvo, basuras y cuanto despojo inmundo" al igual que las casas, por lo tanto, se solicitaba a las autoridades "ordenar a los indolentes, mas limpieza interna en sus viviendas que pueden ser pobres, más aún, miserables, pero aseadas (sic)" y, además de una mayor vigilancia para evitar que recrudeciera nuevamente el cólera (Las malas..., 18 nov. 1887).

Estas conclusiones de la prensa derivaban de que además del modo general de vida de los sectores populares, se insistía en las falencias respecto de los hábitos de aseo personal, apuntando a la limpieza individual con el objetivo de disciplinar el cuerpo, ocultando sus “olores y sus sudoraciones cuando no su anulación" (Barrán, 1989, p.53). Así como también, en los modos alimenticios, ya que si bien era sabido que las primeras frutas y legumbres sin madurar eran propicias a provocar el cólera, se sostenía que las personas del pueblo no empleaban ningún tipo de recaudo para evitarlo, a lo que se sumaba, se decía, el consumo de vinos y otras bebidas adulteradas (Advertencias..., 17 dic. 1886). Además, se agregaba que usaban la misma agua con diversos fines: bebida, baño, lavandería y letrina, como ocurría, "en la acequia del Jarrillal, que prove[ía] de agua Panquegua y la Chimba, [con] los peones que trabajan en la sierra (sic)" (Policía..., 22 dic. 1886).

Por ello, las autoridades solicitaban que no se cometieran estos tipos de excesos, ya que estos generaban un caldo de cultivo para el desarrollo de enfermedades infectocontagiosas y en especial del cólera (Buenos Aires, 1887); a raíz de lo cual se suspendió el carnaval, ya que allí se cometían todo tipo de demasías que perjudicaban a la salud y las buenas costumbres (La supresión..., 5 ene. 1887). Asimismo, se aconsejaba como necesario evitar los excesos físicos y mentales como la tristeza, el enojo y el miedo (Contra..., 14 nov. 1886). Estas 
recomendaciones buscaban influir sobre la moral de los sujetos, haciéndoles comprender la utilidad de las medidas tomadas por el gobierno y la mejora que generaban en la calidad de vida, ello en un contexto de representaciones en el que siguiendo los planteos de la medicina de antaño, se sostenía que el abatimiento moral y el miedo predisponía al sujeto a sufrir el contagio (Delumeau, 1989).

Por otra parte, tal como menciona un estudio de Carbonetti (2007) para el caso de la epidemia de cólera en la provincia de Córdoba durante 1867 y 1868, los sectores sociales de mayor poder adquisitivo optaron por estrategias más eficaces para evitar el sufrimiento (como medicamentos, productos suntuarios), a diferencia de los sectores más vulnerables que contaban con posibilidades reducidas para enfrentarla. Situación favorable que se completaba con una mejor presentación de servicios municipales y en la provisión de agua potable (conexiones domiciliarias, surtidores y reparto), a la que se agregaba en los casos más graves, la posibilidad de emigrar hacia las propiedades rurales para evitar los contagios (Cirvini, 1989). Probablemente esta medida "anticontagionista" era deudora de la creencia de que los focos de propagación se encontraban desigualmente distribuidos en el campo que en la ciudad (Caponi, 2002c). Aún en los albores del siglo XIX, estas diferencias sociales continuaban, tal como observan Carbonetti, Gómez, Torres, (2013, p.281), durante el desarrollo de la gripe en la provincia de Salta, en donde los "privilegios políticos, económicos y sociales daban ventajas a los sectores de la alta sociedad" y, de este modo, esa enfermedad afectaba más a los grupos infantiles y de menores recursos.

Asimismo, había que tener en cuenta los factores que se vinculaban con el imaginario de las clases pobres afirmándose que "una de las cosas que más perturba el ánimo en estas circunstancia [era] la falsa idea, propalada entre el pueblo, de la exagerada malignidad que se atribu[ía] al cólera", pues la población creía que todas las víctimas estaban destinadas a morir. Frente a esto, la prensa expresaba que "la experiencia médica, [les] enseñ[ó] que esta enfermedad es fácilmente combatible en su principio (sic)" (La Comisión..., 23 dic. 1886). Teniendo en cuenta estos elementos, se explica que si se implementaba un procedimiento riguroso, basado en un estricto régimen alimenticio, de limpieza personal y de los ambientes se podía evitar todo tipo de contagio, pero para ello se creía fundamental el "apoyo" y "obediencia" de todos los pobladores. En este sentido, se consideraba que un "plan científico fijado de antemano [era] el remedio más eficaz y decisivo para evitar el peligro y destruir el mal en su origen; en tanto que si se desobedec[ían] las precauciones que el buen sentido y la práctica de largos años han puesto en evidencia, los pueblos 'paga[ban] con la muerte' la falta de cumplimento y su funesta terquedad" (La Comisión..., 23 dic. 1886; énfasis del original). Como se puede apreciar, se asignaba una fundamental importancia a las conductas individuales pero también a los comportamientos sociales colectivos como medidas para prevenir la enfermedad (Cueto, 1997).

En síntesis, a través de estos reglamentos se buscaba delimitar los sectores de la ciudad donde debían habitar los enfermos y así establecer una serie de normas que indicaran cuándo se podía salir, cómo, a qué hora, qué debían hacer en sus casas, qué tipo de alimentación debían ingerir. Esto, además, de vetarles tal o cual clase de contacto, los obligaba también a presentarse frente a inspectores o dejarlos ingresar en sus viviendas. En definitiva, buscaban disciplinar las formas de vida de un sector definido de la población (Foucault, 2006). 
Dentro de este clima discursivo que enfocaba su dedo acusador a las clases pobres también hubo sujetos pertenecientes a la elite que se solidarizaron con aquellas, donando dinero (Donativo..., 22 dic. 1886) o realizando campañas para recaudar fondos destinados a aliviar sus desgracias siempre creciente (Juan..., 22 dic. 1886). También es destacable el accionar de ciertos médicos que no aceptaban la remuneración por los servicios prestados o lo donaban para invertir en medicamentos (Digno..., 23 dic. 1886) o en el Asilo de Huérfanos (Desprendimiento..., 12 ene. 1887). Incluso, es remarcable el caso de una mujer distinguida, quien albergaba en su vivienda unos veinteniños huérfanos, brindándoles comida y techo (Notas..., 13 ene. 1887). En este sentido, tal como menciona Folquer (2011), más allá de los egoístas, de aquellos sujetos que solo buscaban su propio beneficio o escapar del peligro, hubo individuos que colaboraron desde diferentes lugares en la causa. De todos modos, es claro que esto no implicaba una modificación en el discurso general de la elite con respecto a los sectores populares y a las enfermedades, pues el ejercicio de la caridad consistía en evitar que los pobres se convirtieran en propagadores de infección con el fin de soslayar el contagio hacia la elite y sus sectores de sociabilidad, es decir, que la caridad, basada en una relación jerárquica entre el que da y el que recibe, estaba mediatizada, en este caso, por el peligro que entrañaban los sujetos de escasos recursos en cuanto foco difusor de los gérmenes coléricos (Moro, 2003). A ello se sumaba, que la caridad era uno de los principales ejes del cristianismo y del dogma de la Iglesia (Fogelman, 2000). De esta forma, según Laqueur (feb. 1983), los pobres pasaron de ser objetos de caridad a serlo de la administración del Estado. Según plantea Caponi (2000, p.10), "no existe un ruptura absoluta ... hay un vínculo entre una ética fundada en la caridad y compasión, y una asistencia dirigida". De este modo, ambas pueden ser pensadas como complementarias, una esencialmente compasiva, fundada en la caridad y el castigo y la otra, racionalista y utilitaria, basada en la exclusión y la normalización, que haría de esos sujetos "peligrosos" sujetos dóciles (Caponi, 2000).

No obstante, más allá de todas las explicaciones científicas, el discurso de la elite siguió apelando a elementos religiosos, interpretando las enfermedades como un castigo divino y sanción social (Ponte, 1999), articulando un mensaje en torno de Dios, los pecados mortales y la moral de los sujetos. En este sentido, se consideró necesario que los jefes de familia hicieran entender a los peones y sirvientes, es decir, a la gente pobre, que ensuciar el agua era un "pecado mortal"; a su vez, las autoridades, los sacerdotes y los predicadores también fueron comprometidos en difundir la idea de la importancia de las aguas limpias (Policia..., 22 dic. 1886). Tanto las autoridades políticas y eclesiásticas como los miembros de la elite tenían la responsabilidad de hacer comprender a este grupo social "que comet[ía] un pecado mortal, porque causa[ba] la muerte de muchos individuos y la desgracia y el sufrimiento de su familia desamparada". Para la gente pobre, "no ha[ía] más que un pecado capital, que jamás [podía] merecer el pecado de Dios y [era] trabajo en dia festivo, destinado para todos los vicios; pero [era] necesario hacerle comprender que hay un pecado mayor, cual [era] el de echar suciedad al agua con que se envenena[ba] y causa[ba] la muerte de muchos (sic)" (Policia..., 22 dic. 1886).

Así, la religión no solo ofrecía una referencia ética para los comportamientos deseados y censurados, con una proporcional distribución de premios y castigos ultraterrenos, sino 
que servía a los fines de mantenimiento del orden social en momentos de crisis. De tal forma, en pleno pico de la epidemia, el ministro de la Orden Tercera de San Francisco convocaba a la población a la iglesia matriz para decir una plegaria con el fin de pedirle a Dios que se "digne a suspender el terrible castigo que ha descargado sobre este pueblo" (Policia..., 22 dic. 1886), ya que las acciones individuales no bastaban, siendo necesario las imploraciones colectivas (Delumeau, 1989). Así, estaba presente la idea de un Dios vengador, propagador de la enfermedad e inquisidor de los malos hábitos y costumbres, lo que hacía necesario las preces del pueblo para que el "Todopoderoso" diera por terminado el flagelo (Folquer, 2011). Según la prédica de ciertos religiosos, era necesario el arrepentimiento de la población, ya que se atribuía el origen de la epidemia a los pecados de los pobladores, discurso que debió haber tenido una recepción favorable entre la población (Cueto, 1997). ${ }^{10}$

De tal forma, según Folquer (2011), un sector de la jerarquía eclesiástica le adjudicó a las conductas desordenadas e inmorales, vinculadas a la sanción de las entonces "leyes laicas", las causas del castigo divino. En relación a esto, el obispo de Cuyo, monseñor Wenceslao Achával, realizó una crítica pública contra la sanción del Registro Civil en la vecina provincia de San Juan, ya que consideraba que la creación de esta institución privaba a los curas de un importante ingreso económico: "se nos quitan los cementerios secularizándoles y privando a la autoridad eclesiástica de toda inspección en los cementerios" (Folquer, 2011, p.83). Frente a esta situación, la Iglesia puso de manifiesto una serie de medios de salvación (algunos vigentes desde antaño) para liberar a la población de la muerte y de las penas en el más allá (Folquer, 2011), siendo uno de estos, los sufragios. A modo de ejemplo, la señora Dionisia Santillán, vecina de la ciudad de Mendoza, solicitaba a su albacea en su testamento, que donara la suma de cincuenta pesos para que se rezase una novena de misas en bien de las almas de aquellos sujetos que morían de cólera (Lemos, 12 jun. 1888). Así, el bien material se espiritualizaba a través de la realización de sufragios para los más necesitados, ocupando un lugar clave en la "economía de salvación".

Sin embargo, cuando la epidemia comenzó a disminuir se solicitó nuevamente la intervención de Dios para que el cólera no volviera a recrudecer por las malas costumbres de los pobres, por sus modos de vida, su falta de higiene personal y aseo de sus viviendas, sus malos hábitos de alimentación y sus inmorales conductas excesivas (Policia..., 22 dic. 1886). En este sentido, la prensa manifestó que sería doloroso que si por desgracia tuvieran que enfrentar un nuevo avance del cólera se "volviera á presentársenos aquel cuadro de miseria y de horror, acentuado con tintas mas sombrias aún, debido á la criminal e insólita desidia, no ya de la autoridad, sino de aquellos mismos que en medio a una existencia desordenada y semi-animal, son los primeros destinados a caer, por su propia culpa (sic)" (Las malas..., 18 nov. 1887).

Como se ve, en la urgencia de la epidemia, era necesario buscar potenciales culpables con quien descargar los malestares colectivos, aplicando una serie de medidas profilácticas que pusieran fin al flagelo y, de este modo, subsanar los pecados de la población (Delumeau, 1989).

Finalmente, cabe mencionar que si bien los religiosos brindaron su ayuda a las autoridades civiles para combatir la epidemia, en ciertas ocasiones provocaron obstáculos ya que algunos eclesiásticos pidieron a la población que no aceptaran las medidas profilácticas 
proveniente de los filantrópicos de la Cruz Roja, ya que eran masones y su misión era contraria a la Iglesia (Mal..., 23 dic. 1886). No hubo una conducta homogénea, pues en una actitud contraria a lo divulgado por estos últimos hubo sacerdotes que formaban parte de esta comisión y brindaban los socorros espirituales a las víctimas del flagelo que se hallaban en el lazareto y el barrio donde residían (El cólera..., 27 dic. 1886). De esta forma, el campo científico no resultó ajeno al ámbito religioso, sino que por el contrario ciertos principios médicos fueron aliados de la fe siempre que no atentaran contra ésta. No obstante, posteriormente, en algunas ocasiones fueron cuestionados por asociarse con cuestiones laxas y luego con el positivismo (Castelfranco, 2014).

\section{Consideraciones finales}

El grupo dirigente mendocino durante el azote de la epidemia de cólera desplegó una serie de medidas profilácticas - tanto vinculadas a las ideas contagionistas como anticontagionistas - con el fin demejorar el estado sanitario de la ciudad y la población. No obstante, estas medidas profilácticas fueron aplicadas con mayor intensidad sobre las prácticas y costumbres de los sectores populares, ya que las representaciones le habían adjudicado la noción de peligro a ellos y sus espacios. Las críticas hacia estos sujetos estuvieron focalizadas en una serie de puntos recurrentes: la suciedad y el desaseo de sus viviendas, los malos hábitos alimentarios y sus vicios o excesos, sus vestimentas, su atmósfera contaminada, su aseo personal. Por ello, desde la esfera estatal, comenzaron a aplicarse una serie de dispositivos de control, como la exclusión y vigilancia, que buscaron erradicar los malos hábitos de estos grupos y la insalubridad de sus espacios.

Si bien el cólera atacaba tanto a los ricos como a los pobres, no los afectaba de igual manera, ya que los medios e instrumentos de unos y otros eran diferentes, contando los sectores adinerados con una mejor alimentación y condiciones de higiene, asistencia médica y medicamentos, además, de que en algunas ocasiones las políticas públicas los beneficiaban.

De este forma, el Estado reglamentaba las prácticas de los sectores populares en el ámbito público, que abarcaba incluso la intimidad de estos, mientras que los jefes de familias acomodadas lo hacían en lo privado (aun cuando estos mismos en variadas ocasiones escapaban a las regulaciones estatales), ya que consideraban que solo estos eran los causantes y propagadores del cólera. A fines del siglo XIX, la enfermedad era para la elite una cuestión de asunto privado, mientras que para los sectores populares era una cuestión pública, ya que el tema salud funcionaba como un campo donde se legitimaba la intervención del Estado para poder prevenir las dolencias infectocontagiosas que implicaba, en sus políticas de disciplinamiento, una cierta cuota de violencia física (desplazamientos y segmentaciones del espacio urbano) y simbólica (violación de su espacio privado) sobre estos sujetos. De este modo, la epidemia de cólera permitió activar el proyecto "civilizador" que apuntaba a disciplinar los hábitos privados de los sectores populares, aplicando una serie de dispositivos de control que buscaban normalizarlos y homogeneizarlos en concordancia con los valores imperantes. En este sentido, las enfermedades fueron adquiriendo un carácter no solo biológico sino también social. Así, los hábitos de estos grupos fueron moldeándose según los discursos de la elite basados en la higiene y las prácticas profilácticas y terminaron siendo 
interiorizados como resultado de una resignada aceptación de iniciativas disciplinares del Estado moderno.

Por último, se pudo observar que a la hora de aplicar las medidas sobre dichos sectores, los discursos del grupo dirigente estuvieron basados en argumentos científicos e higiénicos, pero también religiosos y morales. La explicación en clave religiosa permitía articular el mensaje en torno de Dios y los pecados mortales con la moral y acciones de los sujetos y los grupos, pues probablemente esta justificación calaba más profundo, debido al arraigo de la cosmovisión religiosa.

\section{NOTAS}

${ }^{1}$ Las representaciones se hacen presente por medio de una imagen que está ausente, produciéndose una relación decodificable entre el signo y el referente significado, aunque ello no implica que siempre se lo descifre tal como se debería. Los sujetos por medio de éstas incorporan las divisiones del mundo social a través de esquemas de clasificación y de juicios, lo que permite pensar los sistemas de percepción y de juicio y las fronteras que atraviesan el mundo social (Chartier, 1996). Tal como plantea Herlizch (2005, p.60; énfasis del original), "a dupla oposição'saúde-doença' e 'indivíduo-sociedade', que organiza a representação, dá sentido à doença. Por meio da saúde e da doença, temos acesso à imagem da sociedade, de suas 'imposições'".

${ }^{2}$ A partir de entonces, comenzó a denominarse la "ciudad vieja", sin embargo, este corte abrupto permitió la conformación de una "nueva ciudad" con un planteamiento "moderno y progresista", ubicada al SE de la antigua. Esta última perdió sus usos administrativos y políticos y allí se instaló el matadero, el hospital, el lazareto, los conventillos, los prostíbulos. No contaba ni con calles empedradas ni arboladas, así como tampoco con agua corriente ni cloacas, a pesar de acoger una gran cantidad de población, en especial a los sectores populares. Por su parte, la nueva ciudad albergó todas las reparticiones y oficinas públicas y allíse desplazaron los grupos de mayor poder adquisitivo (Ponte, 1999).

${ }^{3}$ El hecho de traer un destacado facultativo constituyó una estrategia más de la elite para modernizar la estructura sanitaria. Coni realizó un estudio de las condiciones higiénicas en las que se encontraba la ciudad, dentro del cual se destacó la concreción de un "censo habitacional". En éste se analizaron las condiciones en que vivían los sujetos en los conventillos, lo que da cuenta de la activación de un nuevo dispositivo de control y vigilancia sobre estos espacios y sus residentes. Este instrumento le permitió al Estado, definir matrices mentales y discursivas para construir una imagen determinada de la población y, así, orientar las políticas públicas y sociales para ser aplicadas sobre los grupos de riesgo (Otero, 1998).

${ }^{4}$ La teoría miasmática planteaba que las emanaciones y efluidos de materiales orgánicos en descomposición eran las propagadoras de las enfermedades infectocontagiosas, ya que estos transportaban partículas que al ingresar al cuerpo humano provocaban la dolencia. Por ello, se creía que los miasmas infectaban el aire e incubaban epidemias (Carbonetti, 2007).

${ }^{5}$ Lovisolo (1996, p.26; énfasis del original) plantea que el positivismo puede ser entendido como "la creencia en la capacidad de la ciencia de 'cerrar' el campo de conocimiento, sea que ese cerramiento ya haya sucedido o venga a realizarse en el futuro. En este dimensión, se contrapone a la visión 'abierta' o 'inagotable' del conocimiento y de la actividad científica".

${ }^{6}$ Se parte del concepto de elite desarrollado por Losada (2008), quien considera que la alta sociedad porteña de la Belle Époque constituyó un "actor colectivo", en tanto sus actores compartían una forma y estilo de vida que les daba cohesión y les permitía identificarse como grupo social de pertenencia. Este estaba caracterizado por la heterogeneidad y su punto de contacto estaba dado a través de la vida social y cultural de los sujetos, aun cuando su poder político, económico y su sofisticación cultural podían variar. Se considera que los altos cargos políticos estaban dirigidos por miembros de esta elite, de este modo, la elite política integraría la social, no obstante, esta última excedería a la política.

${ }^{7}$ Durante la epidemia de cólera en Buenos Aires, una de las medidas fue la implementación de la cremación de los cadáveres (Fiquepron, 2015), incluso algunos lazaretos contaban con este sistema y una sala de autopsia (Álvarez, 2004), a diferencia de Mendoza que aún en 1940 no poseía hornos. 
${ }^{8}$ No obstante, no hay registros oficiales precisos acerca de la cantidad de muertes a causa del cólera, variando de acuerdo al autor (Céspedes, 1938; Cirvini, 1989; Semorile et al., 1988).

${ }^{9}$ Durante 1870 y 1880 todos los sectores de la sociedad sufrían las mismas enfermedades infectocontagiosas. Recién en 1920 y 1930 los grupos más pobres comenzaron a morir por causas distintas a las de los sectores de mayor poder adquisitivo (Armus, 2000).

${ }^{10} \mathrm{Si}$ bien el autor hace referencia a otra coordenada espacio-temporal, esto es, a la malaria desarrollada en Perú en 1932, se consideraque se vincula al caso de análisis.

\section{REFERENCIAS}

ADVERTENCIAS...

Advertencias. La Palabra. 17 dic. 1886.

ÁLVAREZ, Adriana.

La aparición del cólera en Buenos Aires

(Argentina), 1865-1996. Historelo: Revista de

Historia Regional y Local, v.4, n.8, p.172-208. 2012.

ÁLVAREZ, Adriana.

El rol de los lazaretos en el control del cólera y la fiebre amarilla: Buenos Aires, 1870-1915. História Revista, v.9, n.2, p.287-317. 2004.

\section{ARGENTINA.}

Ministério de Educación. Educ.ar. Mapoteca. Disponível em: <http://mapoteca.educ.ar/.files/ index.html.1.27.html>. Acesso em: 17 dez. 2018. s.d.

ARMUS, Diego.

La ciudad impura: salud, tuberculosis y cultura en Buenos Aires, 1870-1950. Buenos Aires: Edhasa. 2007.

ARMUS, Diego.

Abordagens disciplinares: legados y tendencia en la historiografía sobre la enfermedad en América Latina moderna. In: Minayo, Maria Cecília de Souza; Coimbra Jr., Carlos (Org.). Críticas e atuantes: ciências sociais e humanas em saúde na América Latina. p.183-205. 2005.

ARMUS, Diego.

El descubrimiento de la enfermedad como problema social. In: Lobato, Mirta (Dir.). $E l$ progreso, la modernización y sus límites, 1880-1916. Buenos Aires: Sudamericana. p.507-552. 2000.

BARRÁN, José Pedro.

Historia de la sensibilidad en el Uruguay. Uruguay: EBO. 1989.

BUENOS AIRES.

Departamento Nacional de Higiene. Instructivo para prevenir a la República Argentina contra la epidemia de cólera. Buenos Aires: DNH. 1887.

CAPONI, Sandra.

Entre miasmas y microbios: la vivienda popular higienizada. Cadernos de Saúde Pública, v.18, n.6, p.1665-1674. 2002a.
CAPONI, Sandra.

Trópicos, microbios y vectores. História, Ciências, Saúde - Manguinhos, v.9, supl., p.111-138, 2002b.

CAPONI, Sandra.

La generación espontánea y la preocupación higienista por la diseminación de los gérmenes. História, Ciências, Saúde - Manguinhos, v.9, n.3, p.591-608. 2002c.

CAPONI, Sandra.

Da compaixão à solidariedade: uma genealogia da assistência médica. Rio de Janeiro: Editora Fiocruz. 2000.

CARBONETTI, Adrián.

Cólera y conflicto en la ciudad de Córdoba, Argentina (1867-1868). Boletín Mexicano de Historia y Filosofía de la Medicina, v.10, n.2, p.7178. 2007.

CARBONETTI, Adrián; GÓMEZ, Néstor J.; TORRES, Víctor. E.

La gripe española y crisis de mortalidad en Salta, Argentina: a principios del siglo XX. Historelo: Revista de Historia Regional y Local, v.5, n.10, p.269-300. 2013.

CASTELFRANCO, Diego.

La voz de la Iglesia y el discurso católico sobre la ciencia en la Argentina de fines del siglo XIX (1885-1895). Itinerantes: Revista de Historiay Religión, n.4, p.135-161. 2014.

CERDÁ, Juan Manuel.

Mercado de trabajo y las condiciones de vida en Mendoza acomienzos del siglo XX. Mundo Agrario, v.6, n.12. Disponible en: <http://www. memoria.fahce.unlp.edu.ar/art_revistas/pr.523/ pr.523.pdf>. Acceso en: 10 dic. 2018. 2006.

CÉSPEDES, Conrado.

La epidemia de cólera en 1886-87: su aparición y desarrollo en Mendoza. Junta de Estudios Históricos de Mendoza, p.201-217. 1938.

CHARTIER, Roger.

El mundo como representación: estudios sobre historia cultural. España: Gedisa. 1996. 
CHAVES, Cleide de Lima.

Epidemias e quarentenas no Brasil e no Rio da Prata no século XIX. Estudios Historicos, año 5, n.11. Disponible en: <http://www. estudioshistoricos.org/11/art.7\%20-\%20 Epidemias\%20e\%20quarentenas\%20-\%20 CLEIDE\%20DE\%20LIMA.pdf>. Acceso en: 10 dic. 2018. 2013.

CIRVINI, Silvia.

El ambiente urbano en Mendoza a fines del siglo XIX: la higiene social como herramienta del proyecto utópico del orden. In: Rodríguez Lapuente, Manuel; Cerutti Guldberg, Horacio (Comp.). Arturo Roig: filosofía e historia de las ideas. Guadalajara: Unam. p.107-143. 1989.

CONI, Emilio.

Saneamiento de la provincia de Mendoza. Buenos Aires: Biedma. 1897.

CONTRA...

Contra el cólera. El Ferrocarril. 14 nov. 1886.

CORBIN, Alain.

El perfume o el miasma: el olfato y lo imaginario social, siglos XVIII y XIX. México: Fondo de Cultura Económica. 2002.

CUETO, Marcos.

El regreso de las epidemias: salud y sociedad en el Perú del siglo XX. Lima: IEP.1997.

DELUMEAU, Jean.

El miedo en Occidente. Madrid: Taurus. 1989.

DESPRENDIMIENTO...

Desprendimiento y filantropía. El Ferrocarril. 12 ene. 1887.

DIGNO...

Digno de proceder. Los Andes. 23 dic. 1886.

DI LISCIA, María Silvia.

Itinerarios curativos: saberes, terapias y prácticas médicas indígenas, populares y científicas (Región Pampeana, 1750-1910). Tesis (Doctorado en Historia) - Instituto Universitario Ortega y Gasset, Universidad Complutense de Madrid, Madrid. 2000.

DONATIVO...

Donativo. Los Andes. 22 dic. 1886.

EL CÓLERA...

El cólera en San Vicente. El Ferrocarril. 27 dic. 1886.

EL CÓLERA...

¡El cólera! Los Andes. 16 dic. 1886.

EL CUERPO...

El cuerpo médico. El Ferrocarril. 10 nov. 1886.

ENTREMOS...

Entremos en camino. El Ferrocarril. 22 dic. 1886.
FERRARI, Alejandra.

Borrachos eran los de antes... El vino como problema sociocultural y político en San Juan, Argentina, 1880-1910. Rivar, v.1, n.3, p.57-75. 2014.

FIQUEPRON, Maximiliano.

Cadáveres célebres y anónimos: funerales, epidemias y distinción social en Buenos Aires, 1860-1870. In: Gayol Sandra; Kessler Gabriel (Comp.). Muerte, política y sociedad en la Argentina moderna. Buenos Aires: Edhasa. p.227250. 2015.

FOGELMAN, Patricia.

Una cofradía mariana urbana y otra rural a fines del periodo colonial. Andes, n.11. Disponible en: <https://www.redalyc.org/articulo. oa?id=12701109>. Acceso en: 10 dic. 2018. 2000.

FOLQUER, Cynthia.

Cólera morbus y cólera divina: miedo a la muerte e imaginario religioso en Tucumán (Argentina), a fines del siglo XIX. Boletín Americanista, n.62, p.73-96. 2011.

FOUCAULT, Michel.

Seguridad, territorio y población. Buenos Aires: Fondo de Cultura Económica. 2006.

GARGIULO, María Cecilia.

El cólera: oportunidades de control y resistencia populares. Tucumán, 1886-1887. Estudios Sociales, año 21, n.41, p.97-125. 2011.

GONZÁLEZ LEANDRI, Ricardo.

Miradas médicas sobre la cuestión social: Buenos Aires a fines del siglo XX y principios del XX. Revista de Indias, v.60, n.219, p.421-435. 2000 .

HERZLICH, Claudine.

A problemática da representação social e sua utilidade no campo da doença. Physis, v.15, supl., p.57-70. 2005.

HIJIENE...

Hijiene. El Ferrocarril. 3 dic. 1886.

JUAN...

Juan Serafini. Los Andes. 22 dic. 1886.

LA COMISIÓN...

La Comisión Nacional. Los Andes. 23 dic. 1886.

LA CUARENTENA...

La cuarentena. Los Andes. 27 dic. 1886.

LA EPIDEMIA...

La epidemia. Los Andes. 23 dic. 1886.

LAS AGLOMERACIONES...

Las aglomeraciones. El Ferrocarril. 10 dic. 1886.

LAS MALAS...

Las malas condiciones higiénicas. Los Andes. 18 nov. 1887. 
LAQUEUR, Thomas.

Bodies, death, and pauper funerals.

Representations, n.1, p.109-131. feb. 1983.

LA SUPRESIÓN...

La supresión del carnaval. Los Andes. 5 ene. 1887.

LA VERDAD...

La verdad para hacer justicia. El Ferrocarril.

11 ene. 1887.

LEMOS, Julio.

Higienización y demografía. Buenos Aires:

J. Peuser. 1897.

LEMOS, Néstor.

Relato de un relato. Buenos Aires: Colombo. 1973.

LEMOS, Pompeyo.

Testamento de Dionisia Santillán. Protocolo n.435, t.2, p.436 (Archivo General de la Provincia de Mendoza; Mendoza, Argentina). 12 jun. 1888.

LOSADA, Leandro.

La alta sociedad en la Buenos Aires de la Belle Époque. Buenos Aires: Siglo XXI. 2008.

LOS MÉDICOS...

Los médicos de la provincia. La Palabra, p.1. 14 mayo 1926.

LOVISOLO, Hugo.

Comunidades científicas y universidades en la Argentina y Brasil. Redes, v.3, n.8, p.47-94. 1996.

MAL...

Mal proceder. Los Andes. 23 dic. 1886.

MENDOZA.

Municipalidad de la Capital. Memoria desde el 1 enero de 1901 a 31 de diciembre de 1902. Mendoza: Municipalidad de la Capital. 1903.

MENDOZA.

Municipalidad de la Ciudad de Mendoza. Memoria de la Municipalidad de Mendoza correspondiente a los años 1884 ( $2^{\circ}$ semestre), 1885, 1886 y 1887. Mendoza: Municipalidad de la Ciudad de Mendoza. 1888.
MORO, José.

Las epidemias de cólera en la Austrias del siglo XIX.

Oviedo: Universidad de Oviedo. 2003.

NOTAS...

Notas editoriales. La Palabra. 13 ene. 1887.

OBSERVACIONES...

Observaciones consoladoras. La Palabra. 28 dic. 1886.

OTERO, Hernán.

Estadística censal y construcción de la nación: el caso argentino, 1869-1914. Boletín del Instituto de Historia Argentina y Americana Dr. Emilio Ravignani, n.16-17, p.123-149. 1997-1998.

POLICÍA...

Policía de higiene. Los Andes. 22 dic. 1886.

PONTE, Ricardo.

Mendoza: aquella ciudad de barro. Buenos Aires: Conicet. 2008.

PONTE, Ricardo.

La fragilidad de la memoria. Mendoza: Crycit. 1999.

RECLAMO...

Reclamo. Los Andes. 22 dic. 1886.

SALVATORE, Ricardo.

Sobre el surgimiento del estado médico en la Argentina, 1890-1940. Estudios Sociales, año 11, n.20, p.81-114. 2001.

SEMORILE, Adolfo et al.

Historia de la medicina en Mendoza. Mendoza: Editorial propia. 1988.

VALLONE, Silvana.

Los peligros del orden: el discurso positivista en la trama del control social. Mendoza: Ediunc. 2009.

VEZZETI, Hugo.

La locura en la Argentina. Buenos Aires: Paidós. 1985.

UNA IDEA...

Una idea. Los Andes. 21 ene. 1887. 